\title{
Expression of stem cell factor and its receptor c-Kit during the development of intrahepatic cholangiocarcinoma
}

\author{
Tümen Mansuroglu' ${ }^{1}$ Pierluigi Ramadori ${ }^{1}$, József Dudás ${ }^{1}$, Ihtzaz Malik ${ }^{1}$ Kristoff Hammerich ${ }^{1}$, László Füzesi ${ }^{2}$ and \\ Giuliano Ramadori*,1
}

Stem cell factor (SCF) and its receptor, c-Kit, constitute an important signal transduction system with proliferative and anti-apoptotic functions. Besides regulating hemopoietic stem cell proliferation and liver regeneration, it has been implicated in the regulation of human malignancies. However, the cellular expression of the SCF-c-Kit gene system in the liver during cholangiocarcinogenesis has not been studied to date. The protein- and mRNA-expression levels of SCF and c-Kit genes were examined in normal rat liver, in isolated normal rat liver cells and in a thioacetamide-induced rat model of intrahepatic cholangiocarcinoma (CC). Immunohistochemical analysis of the normal liver showed that SCF is expressed in the wall of the hepatic artery and in some cells, which were located along the sinusoids, although it was absent from hepatocytes and biliary epithelial cells. The mRNA analysis of isolated normal liver cell populations revealed a co-expression of SCF- and c-Kit-mRNA in sinusoidal endothelial cells and in Kupffer cells, whereas passaged and cultured liver myofibroblasts (MFs) expressed only SCF. Low levels of the SCF- and c-Kit-mRNA expression could be detected in isolated hepatocytes of the normal liver. Immunohistochemical analysis of the CC tissue showed SCF positivity in proliferating biliary cells $\left(\mathrm{CK}-19^{+}\right)$, in macrophages (ED- $\left.1^{+}\right)$and in MFs ( $\alpha$-smooth-muscle-actin, $\alpha-\mathrm{SMA}^{+}$) of the tumoral microenvironment. c-Kit-positivity could be detected on hepatocytes of the regenerating nodules and on the proliferating bile ducts of CC. Compared with the normal liver tissue, SCF-mRNA from the CC tissue was upregulated up to 20-fold, whereas c-Kit-mRNA was upregulated up to fivefold. These data indicate that several cell populations may become able to express SCF and/or c-Kit during cholangiocarcinogenesis. Therefore, the SCF-c-Kit system may contribute to tumor development, for instance, by inducing proliferation of hepatocytes and of biliary cells and by acting as a surviving factor for CC cells.

Laboratory Investigation (2009) 89, 562-574; doi:10.1038/labinvest.2009.15; published online 2 March 2009

KEYWORDS: stem cell factor; c-Kit; cholangiocarcinoma; liver cirrhosis; Kupffer cells; myofibroblasts

Cholangiocarcinoma (CC) is a primary hepatic malignancy originating from cholangiocytes of the biliary tree and possibly from cholangiocyte progenitor cells. ${ }^{1-4}$ It is the second most common primary hepatic neoplasia, and its incidence has increased within the last three decades. Often, surgical resection offers the only hope for cure, but the majority of patients are found to have unresectable disease on initial presentation and have extremely severe prognoses. ${ }^{5-7}$

Until now, the different forms of carcinogenesis involved in CC are poorly understood. Cancer development, which represents a dynamic process, involves a modification of the original organization and function of a tissue. ${ }^{8}$ Experimental, clinical and epidemiological studies have revealed that chronic inflammation contributes to cancer progression and even predisposes to different types of cancer. $^{9,10}$ A more thorough understanding, such as precisely which cells are the targets of neoplastic transformation, is currently lacking. An emerging hypothesis in the field is that cancer arises and is sustained from a rare sub-population of tumor cells with characteristics that are highly similar to stem cells, such as the ability to self-renew and differentiate. ${ }^{3,11}$

\footnotetext{
${ }^{1}$ Department of Gastroenterology and Endocrinology, Center of Internal Medicine, University of Göttingen, Göttingen, Germany and ${ }^{2}$ Department of Pathology, University of Göttingen, Göttingen, Germany

${ }^{*}$ Correspondence: Professor G Ramadori, MD, Department of Gastroenterology and Endocrinology, Center of Internal Medicine, University of Göttingen, Robert Koch Straße 40, D-37099 Göttingen, Germany.

E-mail: gramado@med.uni-goettingen.de

Received 20 July 2008; revised 13 January 2009; accepted 26 January 2009
} 
Stem cell factor (SCF), the ligand of the c-Kit receptor, constitutes an important signal transduction system with proliferative and anti-apoptotic functions. It has predominantly been depicted as a hematopoietic factor that induces stem cell maturation and differentiation. ${ }^{12,13}$ Besides regulating the hemopoietic stem cell proliferation, SCF has been implicated in inflammatory diseases, tissue remodeling-including fibrosis-and in liver regeneration after liver injury, suggesting that it may serve as a protective factor in tissues that could be susceptible to environmental-toxic injury. ${ }^{14-18}$ However, further studies indicate that, in addition to its physiological functions, SCF plays a critical role in carcinogenesis and is co-expressed with its receptor, c-Kit, in various tumors, implying the possible presence of an autocrine and/or a paracrine loop. ${ }^{19-23}$ In this manner, it seems that several cell populations can express and quickly release SCF upon cellular assault or inflammation. ${ }^{18}$

As SCF produces features that are supposed to be important in cancer development, we investigated the SCFc-Kit-gene expression in the liver of a rat model of toxic inflammation, damage, fibrosis, cirrhosis and cholangiocarcinogenesis. Furthermore, we examined the expression of both genes in isolated cells from the normal liver. Our data showed that hepatocytes and biliary epithelial cells are able to express detectable $\mathrm{c}$-Kit receptor during damage and repair processes up to the development of a CC, and that these cells may become the target of an increasingly expressed SCF.

\section{MATERIALS AND METHODS Materials}

Chemicals were purchased from Merck (Darmstadt, Germany), Applichem (Darmstadt) and Sigma (Steinheim, Germany). Materials for biochemical and immunohistological methods are listed in the appropriate sections.

\section{Animal Groups and Thioacetamide Administration}

Male Sprague-Dawley (SD) rats weighing 330-370 g were used in these experiments. Animals were provided by Charles River (Sulzfeld, Germany) and Harlan Winkelmann (Borchen, Germany), and received humane care according to the guidelines of the local institution and the National Institute of Health. We adhered to the institutional policies and the relevant guidelines for care and use of laboratory animals. All the animal experiments, that were carried out, were approved by the ethics review board and were constantly supervised by the local ethics commission. The animals were divided into two groups, including a control group $(n=20)$ and an experiment group $(n=25)$. They were housed in an animal room with a 12:12-h light-dark cycle and provided with food and water available ad libitum. CC was induced according to the protocol by Yeh $e t \mathrm{al}^{24}$ with a slight modification. The experiment group received $500 \mathrm{mg} / \mathrm{l}$ thioacetamide (TAA) in their drinking water every day up until the time they were killed, whereas the control group received tap water instead of TAA. Four control- and five TAA-treated rats were harvested every fourth week, during the study, to examine the effect of TAA. Overall $80 \%$ of the TAA-treated rats had developed CC by week 16 , and the experiment was stopped at week 18 , when $100 \%$ of the TAAtreated rats had developed CC. Liver tumors were quantified along the surface, and grossly apparent tumors were carefully dissected from the surrounding liver tissue.

\section{Immunohistochemistry}

Immunohistochemical evaluation was performed on $4-\mu \mathrm{m}$ thin, formalin-fixed, paraffin-embedded serial sections and/ or on cryostat serial sections (Reichert Jung, Wetzlar, Germany) using the antibodies listed in Table 1. Briefly, the paraffin-embedded sections were deparaffinized and rehydrated using graded alcohols to phosphate-buffered saline (PBS). Cryostat sections were air dried and used for

Table 1 Antibodies and reagents

\begin{tabular}{llll}
\hline Primary antibody & Catalog $\#$ & Species & Reference \\
SCF & SC-1303 & Goat polyclonal & Santa Cruz (Santa Cruz, CA, USA) \\
C-Kit & A 4502 & Rabbit polyclonal & Dako (Glostrup, Denmark) \\
CK-7 & M 7018 & Mouse monoclonal & Dako \\
CK-19 & Mouse monoclonal & Novocastra (Newcastle, upon Tyne, UK) \\
ED1 & MCA 341R & Mouse monoclonal & Serotec (Düsseldorf, Germany) \\
ED2 & MCA 342R & Mouse monoclonal & Serotec \\
Thy-1 & 555593 & Mouse monoclonal & BD Pharmingen (Sandiego, CA, USA) \\
$\alpha-S M A$ & A2547 & Mouse monoclonal & Sigma (Munich, Germany) \\
PECAM & 803 & Mouse monoclonal & LabGen (Frankfurt, Germany) \\
HepPar-1 & M 7158 & Mouse monoclonal & Dako \\
\hline
\end{tabular}


immunohistochemical studies after fixation for $10 \mathrm{~min}$ in acetone at room temperature. After blocking non-specific binding with $1 \%$ bovine serum albumin (Serva, Heidelberg, Germany) and with $10 \%$ goat serum (Dako, Glostrup, Denmark) containing PBS (Biochrom, Berlin, Germany) for $1 \mathrm{~h}$ at room temperature, a single primary antibody or two (double staining) primary antibodies were incubated overnight at $4{ }^{\circ} \mathrm{C}$ on the sections. Antigens were visualized using two different immunohistochemical methods. For light microscopy, the standard alkaline phosphatase anti-alkaline phosphatase/Fast Red method was used as described before. ${ }^{25}$ Double immunostaining for studies of antigen co-localization was performed using the fluorescent conjugates. The rabbit polyclonal and mouse monoclonal antibodies were detected with an Alexa-555-conjugated goat-anti-rabbit and with an Alexa-488 conjugated goat-anti-mouse secondary antibodies (Molecular Probes, Leiden, The Netherlands). Sections were counter stained with DAPI (Molecular Probes) and observed using an epifluorescence microscope (Axiovert 200M, Zeiss, Jena, Germany). Negative control immunostainings were performed by omission of the primary antibody, using isotype-matching control immunoglobulins.

\section{Western Blot Analysis of TAA-Treated Rat Livers}

Protein was isolated from all control- and TAA-treated (time points: at weeks $4,8,12,16$ and 18 of TAA administration) rat livers, as well as from the dissected CC tissues (at week 18 of TAA administration). Briefly, liver tissue samples were lysed in the RIPA buffer $(25 \mathrm{mM}$ Tris- $\mathrm{HCl} \mathrm{pH} \mathrm{7.6,} 150 \mathrm{mM}$ $\mathrm{NaCl}, 1 \% \mathrm{NP}-40,1 \%$ sodium deoxycholate, $0.1 \% \mathrm{SDS}$ ); the protein concentration was determined using the Bradford method (Pierce, Rockford, IL, USA) and $50 \mu \mathrm{g}$ of proteincontaining samples were processed using sodium dodecyl sulfate polyacrylamide gel electrophoresis (NuPAGE, Novex $4-12 \%$, Bis-Tris gel; Invitrogen) under reducing conditions followed by a protein transfer on a nitrocellulose membrane according to the manufacturer's instructions. Immunodetection was performed according to the ECL-western blotting protocol. Primary antibodies against the SCF and c-Kit were used at $2.5 \mu \mathrm{g} / \mathrm{ml}$ solutions, $\beta$-actin at 1:1000 solution and peroxidase-labeled anti-mouse and anti-rabbit secondary antibodies were each used at a 1:1000 dilution.

\section{Isolation of Different Liver Cell Populations and Culture Conditions from Adult Control Rats}

Hepatocytes (HC) were isolated from normal (healthy) adult rats by means of collagenase treatment in a recirculating in situ perfusion technique and cultured as reported earlier. ${ }^{26}$ Hepatic stellate cells (HSCs) and myofibroblasts (MFs) were isolated by sequential in situ perfusion with collagenase and pronase. ${ }^{26}$ For other non-parenchymal cells, after perfusion with collagenase, hepatocytes were removed by low-speed centrifugation. Non-parenchymal cells were separated from cellular debris and erythrocytes by density centrifugation in a Nycodenz gradient. Sinusoidal endothelial cells (SECs) and Kupffer cells were obtained as reported before. $^{25,26}$

\section{RNA Isolation and Real-Time PCR Analysis}

RNA was isolated from all control- and TAA-treated (time points: at weeks $4,8,12,16$ and 18 of TAA administration) rat livers, dissected CC tissues (at week 18 of TAA administration) and isolated cell populations as described before, ${ }^{26,27}$ Reverse transcription of RNA into cDNA was performed using the Superscript kit (Invitrogen), according to the manufacturer's instructions. Real-time PCR analysis of cDNA was performed with the Abi Prism Sequence Detection System 7000 (Applied Biosystems, Foster City, CA, USA), using the Sybr-Green reaction master mix (Invitrogen) and the primers as shown in Table 2. Primers were synthesized by MWG Biotech (Ebersberg, Germany). The quantity of the PCR products of the genes of interest $(\mathrm{Q})$ was determined by the threshold PCR cycle values $\left(\mathrm{Ct}_{\text {target }}\right)$ following the instructions given by Applied Biosystems, and normalized with the threshold PCR cycle values of the housekeeping gene Ubiquitin $C(U B C)\left(\mathrm{Ct}_{U B C}\right)$ using the formula: $Q=2^{-\Delta \mathrm{Ct}}$ where $\Delta \mathrm{Ct}=\mathrm{Ct}_{\text {target }}-\mathrm{Ct}_{U B C}$, as describedearlier. ${ }^{26,27}$ The quantities of normalized PCR products detected in the livers of treated rats were compared with the values of control rats, and the relative expression was plotted against the observation time. In all cases, two or three series were analyzed in duplicates.

\section{Statistics}

Descriptive statistics, $t$-test and two-way ANOVA for dependent and independent samples and graphs were performed using Statistica 6.0. (StatSoft, Hamburg, Germany).

Table 2 Primers used for quantitative real time RT-PCR

\begin{tabular}{|c|c|c|c|c|}
\hline Gene & Forward primer & Reverse primer & Amplicon length & mRNA location \\
\hline Rat c-kit & $5^{\prime}-\pi \mathrm{C}$ CTG TGA CAG CTC AAA CG-3' & $5^{\prime}$-AGC AAA TCA TCC AGG TCC AG-3' & $171 \mathrm{bp}$ & $455-625$ \\
\hline Rat SCF & $5^{\prime}$-CAA AAC TGG TGG CGA ATC TT-3' & $5^{\prime}$-GCC ACG AGG TCA TCC ACT AT-3' & $217 b p$ & $296-592$ \\
\hline Rat Ubiquitin C & $5^{\prime}$-CAC CAA GAA GGT CAA ACA GGA A-3' & 5'-AAG ACA CCT CCC CAT CAA ACC-3' & $101 \mathrm{bp}$ & $2379-2480$ \\
\hline
\end{tabular}


We used a constant level, $P=0.05$, for rejection of the null hypothesis.

\section{RESULTS}

Gross Appearance of the Liver and Microscopic Features of CC after TAA Administration

After 18 weeks of TAA administration, the incidence of CC increased to $100 \%$ for harvested livers, and $100 \%$ of the treated animals developed macronodular liver cirrhosis (Figure 1a). To identify CC, a gross and light microscopic examination was performed by an experienced pathologist (László Füzesi). Cut surfaces revealed white, round and firm nodules in the background of a macronodular cirrhotic liver. Histopathology revealed an adenocarcinoma with intense desmoplasia, including proliferating ductules with abnormal luminal profiles, enlarged nuclei with hyperchromasia and pleomorphism (Figure 1b). An intense expression of biliary cytokeratins, CK-7 and CK-19, was seen in all neoplastic glands (Figure 1c and d).

\section{Immunohistochemical Identification of SCF-Expressing Liver Cells}

Immunohistochemical analysis of the normal liver showed SCF positivity in the wall of the hepatic artery and the portal vein and in some cells, which were located along the sinusoids, whereas no clean expression could be identified in hepatocytes and in biliary epithelial cells (Figure 2a and c). Serial sections revealed a positive co-expression of SCF and ED-1 in some cells, which were located in the sinusoids (Figure 2a and $\mathrm{b}$ ). The immunohistochemical co-expression of SCF and $\alpha$-smooth-muscle-actin ( $\alpha$-SMA) could be detected in the wall of the hepatic artery and of the portal vein, but not in the pericytes of the hepatic sinusoids (Figure $2 \mathrm{c}$ and $\mathrm{d}$ ).

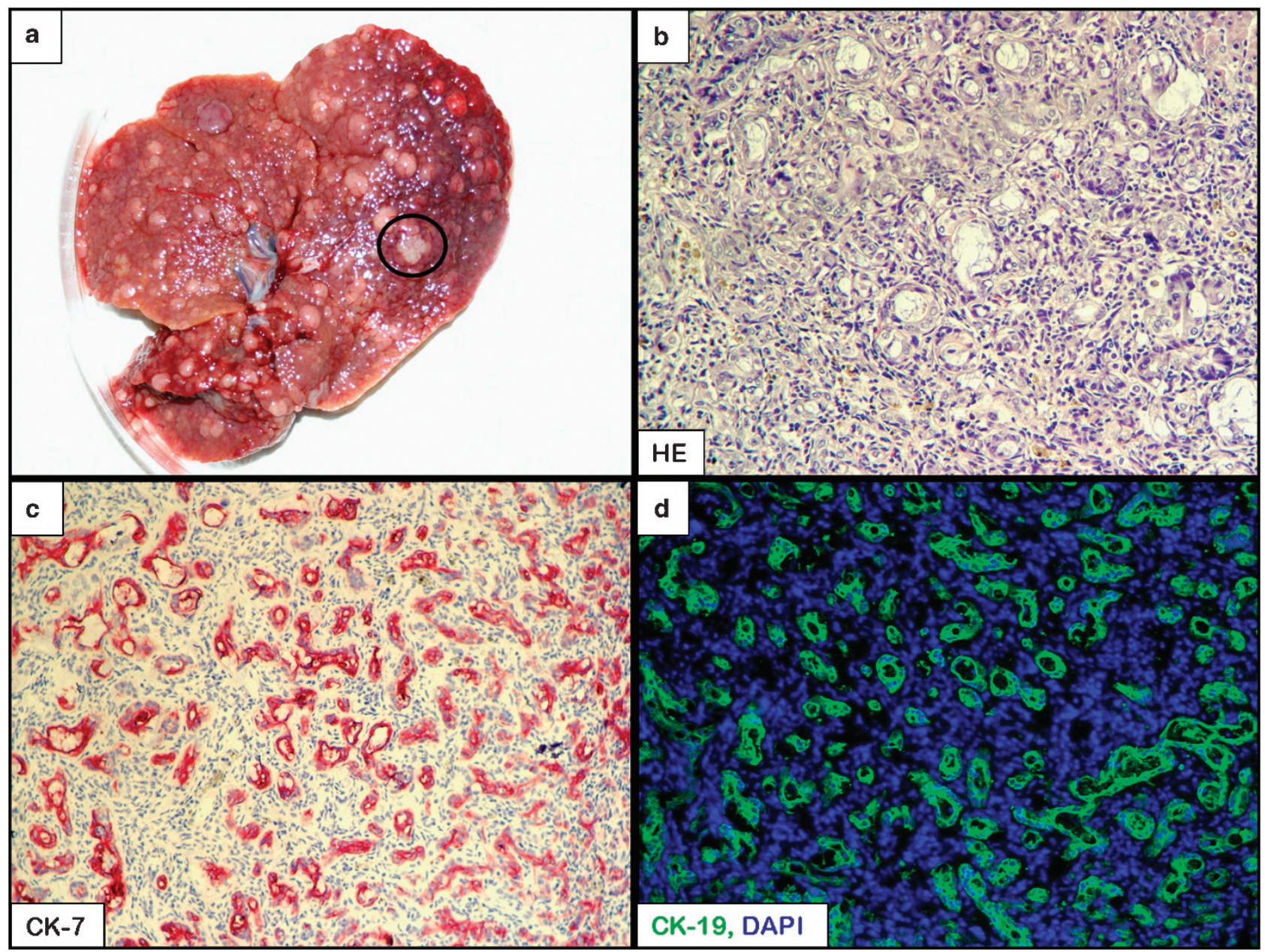

Figure 1 Cholangiocarcinoma after 18 weeks of TAA administration. (a) Shows the gross appearance of a cirrhotic rat liver and the presence of tumoral macronodules with a white mass (circle) after the administration of thioacetamide for 18 weeks. Microscopic examination revealed a glandular appearance of cholangiocarcinoma with hematoxylin and eosin (b), immunohistochemical cytokeratin-7 (c) and immunofluorescence staining with cytokeratin-19 (d). Original magnification $\times 100$. Note the extensive proliferation of bile ducts, which are located within a fibrotic tissue. 


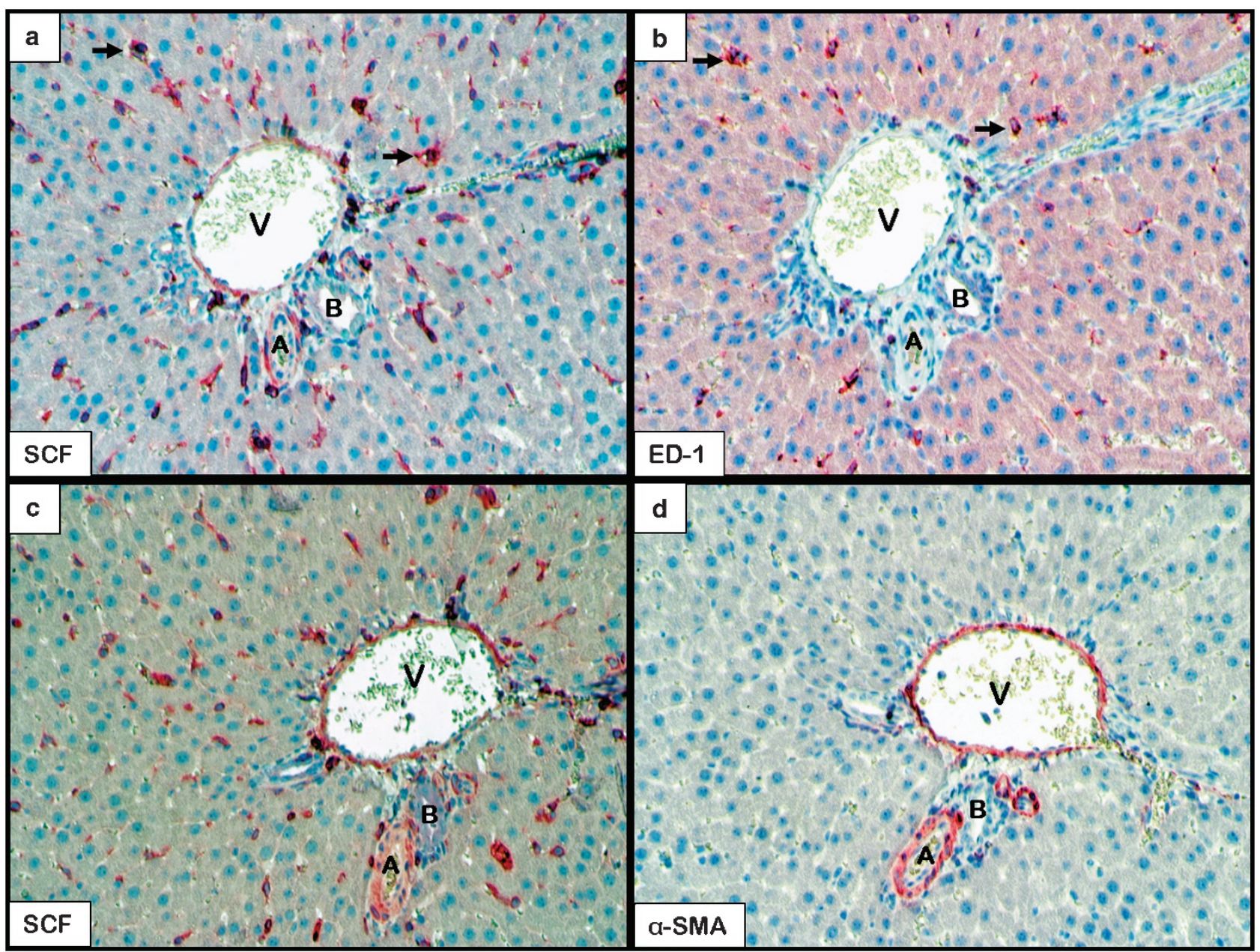

Figure 2 Identification of SCF-expressing cells in serial sections of the normal liver. Immunohistochemical SCF expression could be found in the wall of the hepatic artery (A), in the wall of the portal vein (V) and in scattered cells (arrows) along the sinusoids (a and c). Bile duct epithelial cells (B) and hepatocytes revealed no immunoreaction for SCF. SCF and ED-1 co-expression could be detected in some cells in the liver parenchyma (arrows; panels a and b), whereas a positive co-expression of SCF and $\alpha$-SMA could be found in the wall of the hepatic artery (A) and portal vein (V) (panels $\mathrm{c}$ and d). Original magnification $\times 200$.

SCF-positive cells could be detected along the sinusoids of the regenerating nodules, whereas hepatocytes were SCF negative (Figure 3a). After 18 weeks of TAA administration, ductular cells of the CC showed a strong positive immunoreaction for SCF (Figure 3b). Serial section analysis indicated that, in contrast to the ductular cells of the CC, bile duct epithelial cells of non-tumoral portal fields remained SCF negative (Figure $4 \mathrm{a}-\mathrm{d}$ ). A positive co-expression of $\alpha$-SMA and SCF could be detected in cells, which were located within the fibrotic tissue of the $\mathrm{CC}$ adjacent to proliferating bile ducts, as well as within the cirrhotic liver nodules (Figure $5 \mathrm{a}$ and $\mathrm{b}$ ). Furthermore, numerous SCFpositive cells could be identified between the proliferating bile ducts of the CC and within the regenerating nodules. Serial sections exhibited ED-1-positive mononuclear cells, which co-expressed SCF (Figure 6a and b). Co-localization of SCF and CD-34 pointed out that endothelial cells are positive for SCF as well (Figure $6 \mathrm{c}$ and $\mathrm{d}$ ). In conclusion, the mor- phological and immunohistochemical analysis of serial sections showed that, besides proliferating bile ducts of the CC, SCF-positive cells were mononuclear phagocytes $\left(\mathrm{ED}-1^{+}\right)$, MFs $\left(\alpha-\mathrm{SMA}^{+}\right)$and endothelial cells $\left(\mathrm{CD}-34^{+}\right)$.

\section{Immunohistochemical Identification of c-Kit-Expressing Liver Cells}

The c-Kit immunoreaction could be detected on hepatocytes of the regenerating nodules, which were positive for hepatocyte paraffin-1 (HepPar-1; Figure 7a-d). Ductular cells, which were negative for HepPar-1 and positive for c-Kit, could be found adjacent to the regenerating nodules (Figure $7 \mathrm{c}$ and $\mathrm{d}$ ). The membranous c-Kit expression could also be observed in CK-19-positive ductular cells, which were located in the fibrotic tissue adjacent to the regenerating nodules (Figure 8a and b), as well as in ductular cells of the CC (Figure 9a-d). 


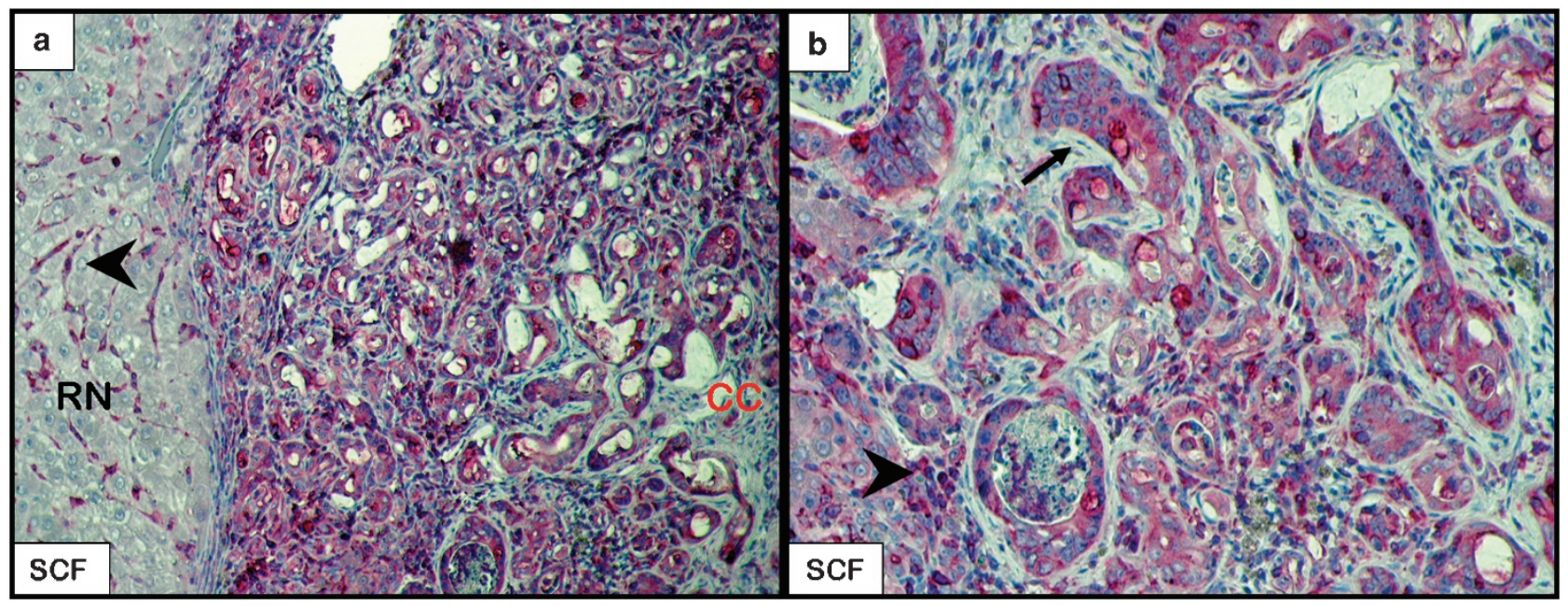

Figure 3 SCF-expressing cells in cholangiocarcinoma and in cirrhotic liver tissue. Immunohistochemical SCF staining in the rat liver after 18 weeks of TAA administration ( $\mathbf{a}$ and $\mathbf{b}$ ). Positive immunoreactivity could be detected in proliferating bile ducts of the CC (arrow), whereas no positivity could be found in hepatocytes of the regenerating nodule (RN). Note that cells, which were located along the sinusoids of the RN and between the proliferating bile ducts of the CC were positive for SCF as well (arrowhead; original magnification panel $\mathrm{a}, \times 100$; panel $\mathrm{b}, \times 200$ ).

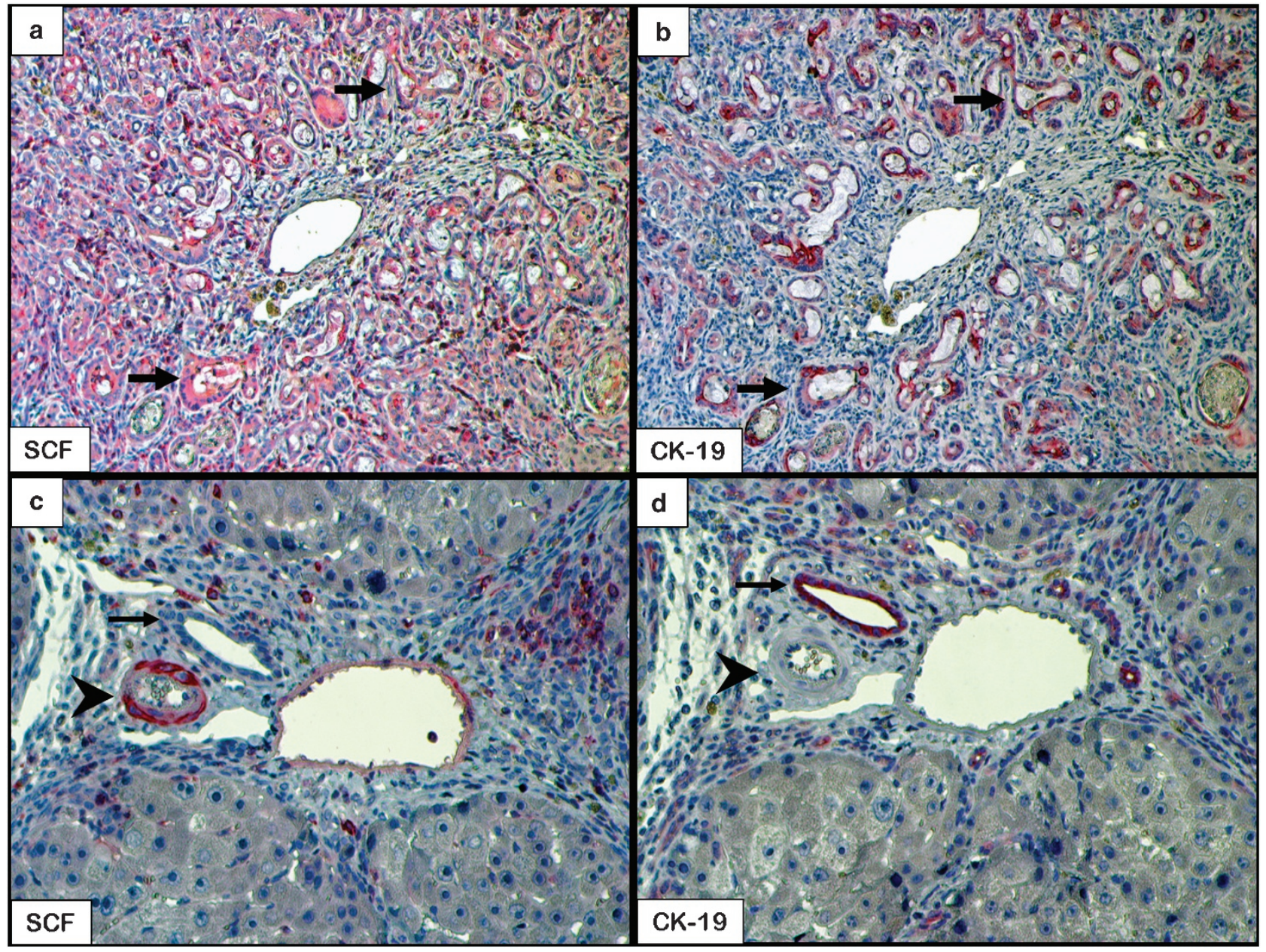

Figure 4 Identification of SCF- and CK-19-expressing cells after 18 weeks of TAA administration. Immunohistochemical investigation of serial sections revealed a positive co-expression of SCF and CK-19 in ductular cells of CC (arrows, a and b; original magnification $\times 100$ ). CK-19-positive bile duct epithelial cells of the portal area in non-tumoral tissue displayed negative immunoreactivity for SCF (arrows, $\mathbf{c}$ and $\mathbf{d}$; original magnification $\times 200$ ). Note that the wall of the hepatic artery showed a strong positivity for SCF (arrowhead). 


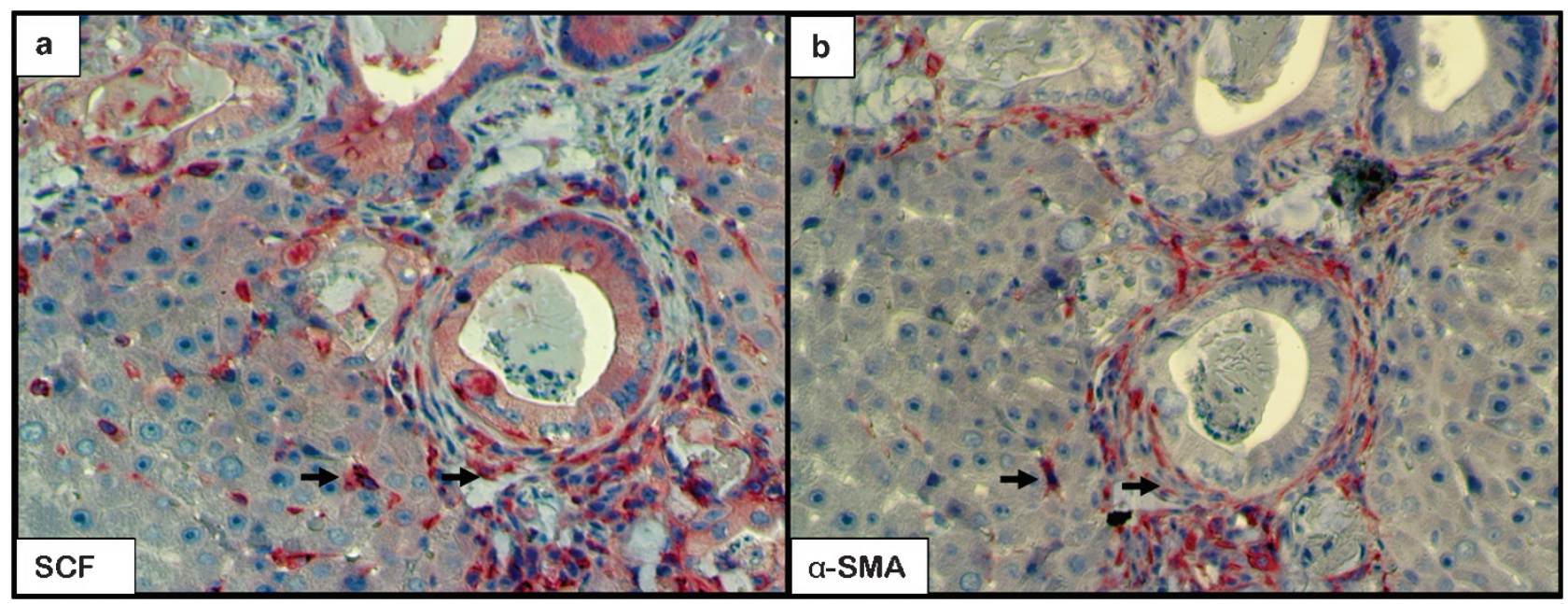

Figure 5 Identification of SCF- and $\alpha$-SMA-expressing cells after 18 weeks of TAA administration. Immunohistochemical staining of serial sections with SCF and $\alpha$-SMA (original magnification $\times 200$ ). Positive co-expression of SCF and $\alpha$-SMA could be detected in cells adjacent to proliferating bile ducts of the CC and within regenerating nodules as well (arrows; $\mathbf{a}$ and $\mathbf{b}$ ).

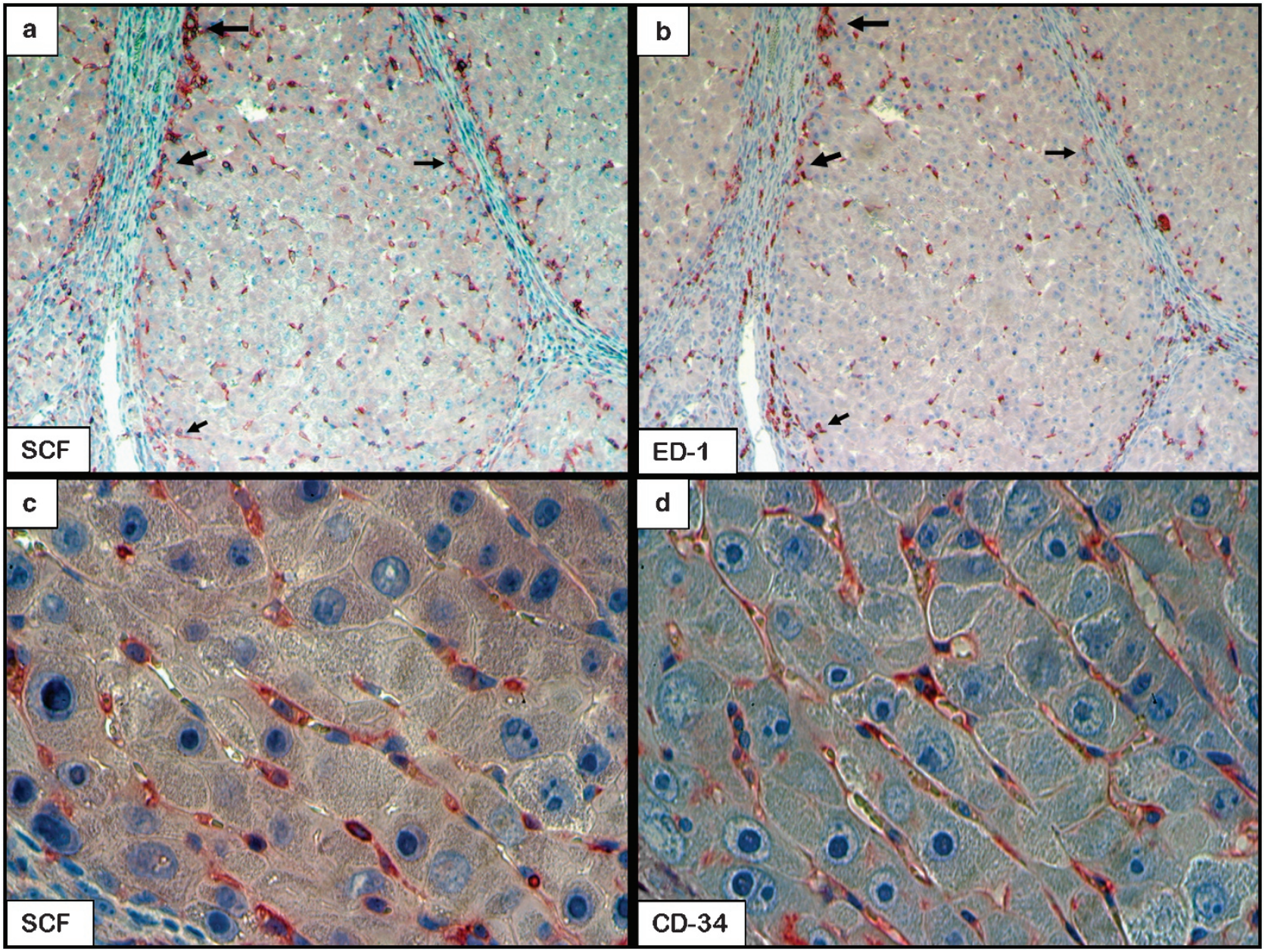

Figure 6 Identification of SCF-, ED-1- and CD-34-expressing cells after 18 weeks of TAA administration. Immunohistochemical staining of serial sections with SCF, ED-1 and CD-34. Cells positive for both ED-1 and SCF could be observed within regenerating nodules (arrows, a and $\mathbf{b}$; original magnification $\times 100$ ). SCF- and CD-34-positive cells were located along the sinusoids of the regenerating nodule (c and $\mathbf{d}$; original magnification $\times 400$ ). 


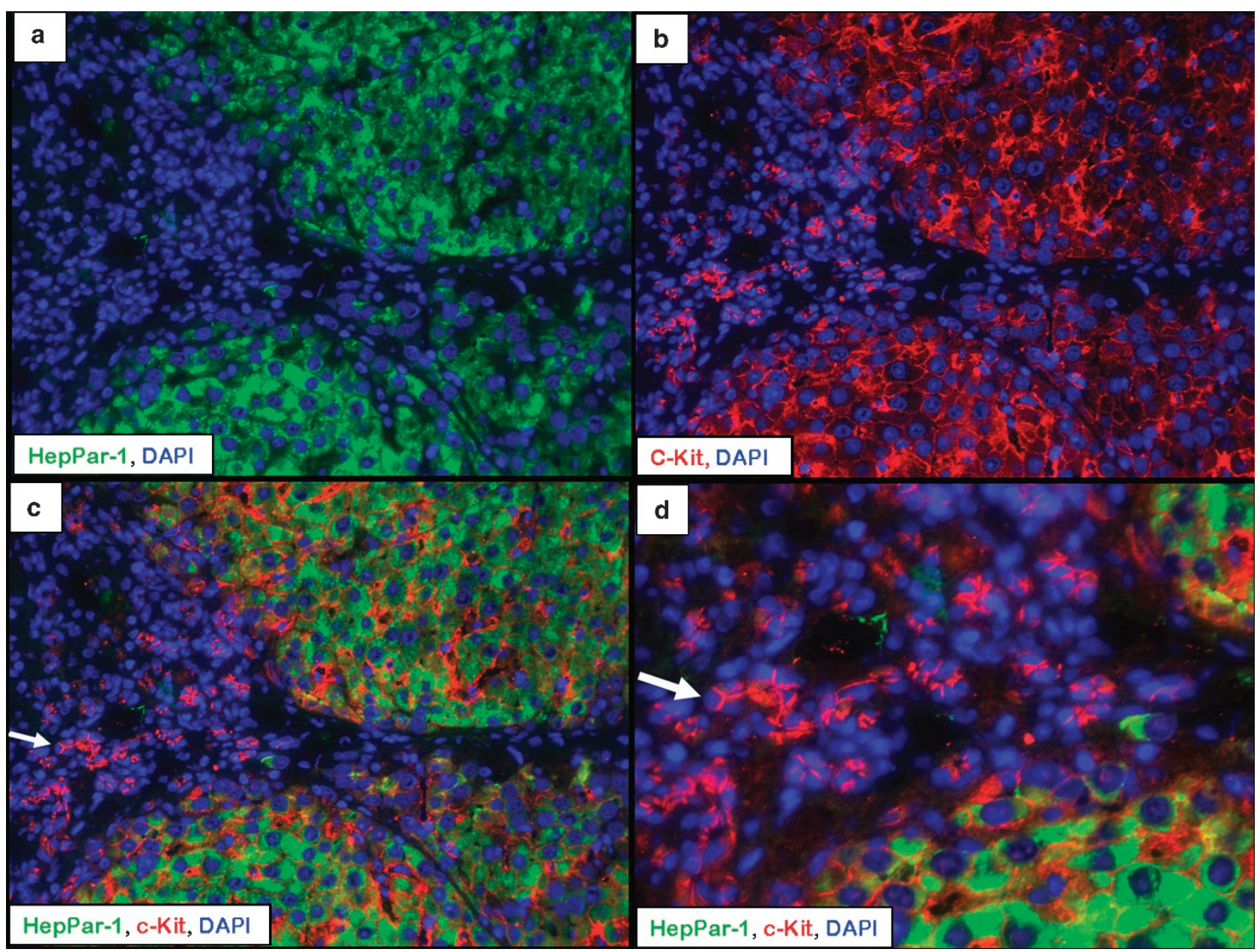

Figure 7 Identification of HepPar-1- and c-Kit-expressing cells after 18 weeks of TAA administration. Double immunofluorescence staining of HepPar-1 (green), c-Kit (red) and cell nuclear counterstaining with DAPI (blue) illustrated separately (a and $\mathbf{b}$ ) and merged (c). Panels a-c and (d) represents a regenerating nodule of a cirrhotic liver showing the co-expression of HepPar-1 and c-Kit (original magnification $\times 200$ ). HepPar-1-negative and c-Kit-positive ductular cells could be observed in the fibrotic tissue adjacent to regenerating nodules (white arrows; $\mathrm{c}$ and d). Panel $\mathrm{d}$ shows a detail of panel $\mathrm{c}$ in a bigger magnification (original magnification $\times 400$ ).

\section{Western Blot Analysis of SCF- and c-Kit-Protein Expression During CC Development}

Western blotting was used to analyze and confirm the increased SCF-protein expression, detected in the CC by immunohistochemistry. Three immunoreactive bands for SCF were observed at 43,31 and $19 \mathrm{kDa}$ (Figure 10). The 43 and $31 \mathrm{kDa}$ correspond to the transmembrane isoforms, whereas the $19-\mathrm{kDa}$ band corresponds to the soluble form of the SCF-protein. ${ }^{28,29}$ The immunoreactive band of the soluble SCF increased progressively throughout the TAA administration period, reaching a maximum at week 18 , and in the CC. The immunoreactive band for the $43-\mathrm{kDa}$ transmembrane isoform was detected in the normal liver and started to increase significantly from week 8 after TAA administration. In contrast to the $43-\mathrm{kDa}$ isoform, the $31-\mathrm{kDa}$ isoform had a lower immunoreactive band and started to increase from 12 weeks after TAA administration. The c-Kit-protein was detected at $145 \mathrm{kD}$, increasing after TAA administration compared with normal liver.

\section{Analysis of SCF- and c-Kit-mRNA Expression During CC Development}

After TAA administration, the mRNA expression of SCF increased gradually up to 20 -fold, reaching a maximum at week 18 and in CC at the same time point $\left({ }^{*} P \leq 0.05\right.$, ${ }^{*} P \leq 0.005$; Figure 11a). Additionally, the $c$-Kit showed a similar upregulation reaching a maximum at week 18 and in CC $\left({ }^{\star} P \leq 0.05,{ }^{*} P \leq 0.005\right.$; Figure $\left.11 \mathrm{~b}\right)$. The c-Kit-mRNA expression was fivefold higher compared with the normal liver and significantly lower compared with that of the SCF-mRNA expression. 


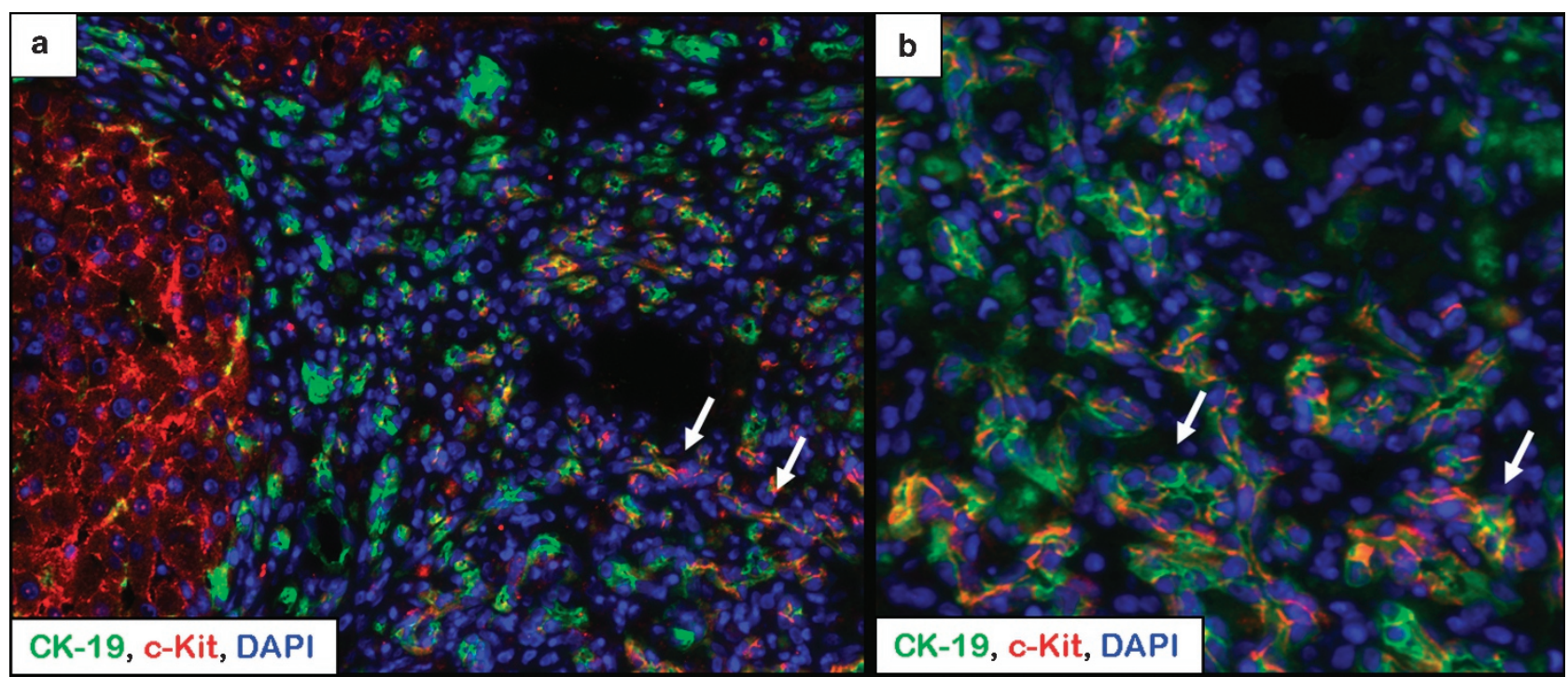

Figure 8 Identification of CK-19- and c-Kit-expressing cells after 18 weeks of TAA administration. Double immunofluorescence staining of CK-19 (green), c-Kit (red) and cell nuclear counterstaining with DAPI (blue). (a) Original magnification $\times 200$; (b) original magnification $\times 400$. Panel a represents a c-Kitpositive and CK-19-negative regenerating nodule. Ductular cells, which were positive for both CK-19 and c-Kit, could be observed in the fibrotic tissue adjacent to regenerating nodules (white arrows; panels a and b).

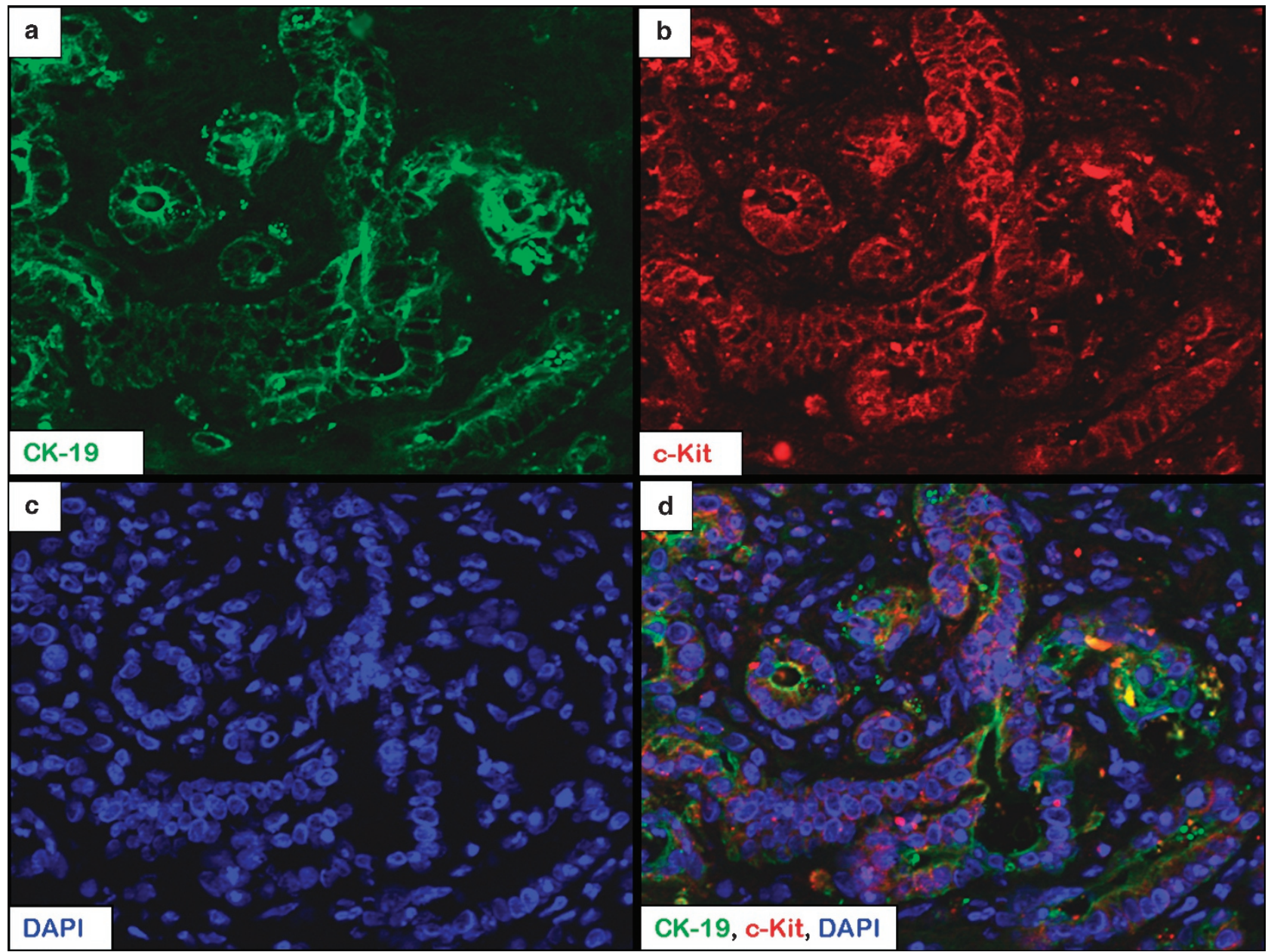

Figure 9 Identification of CK-19- and c-Kit-expressing cells in cholangiocarcinoma. Double immunofluorescence staining of CK-19 (green, a), c-Kit (red, b) and cell nuclear counterstaining with DAPI (blue, c) illustrated separately and merged (d). Original magnification $\times 200$. Ductular cells of CC after 18 weeks of TAA administration display a co-expression of CK-19 and c-Kit (panel d). 


\section{Analysis of SCF- and c-Kit-mRNA Expression in Isolated Normal Rat Liver Cells}

To determine which liver cell populations of the normal liver are able to express SCF and c-Kit, we isolated and cultured hepatocytes, Kupffer cells, HSCs, SECs and liver MFs from the normal rat liver. High levels of the SCF-mRNA expression were detected in Kupffer cells (Ct-mean: 26), SECs (Ct-mean: 28), MFs (Ct-mean: 29,5) and at a lower level in activated HSCs (Ct-mean: 33-35). Low SCF-mRNA expression was also measured in hepatocytes (Ct-mean: 36) (Figure 12a). High levels of the c-Kit-mRNA expression could be found in

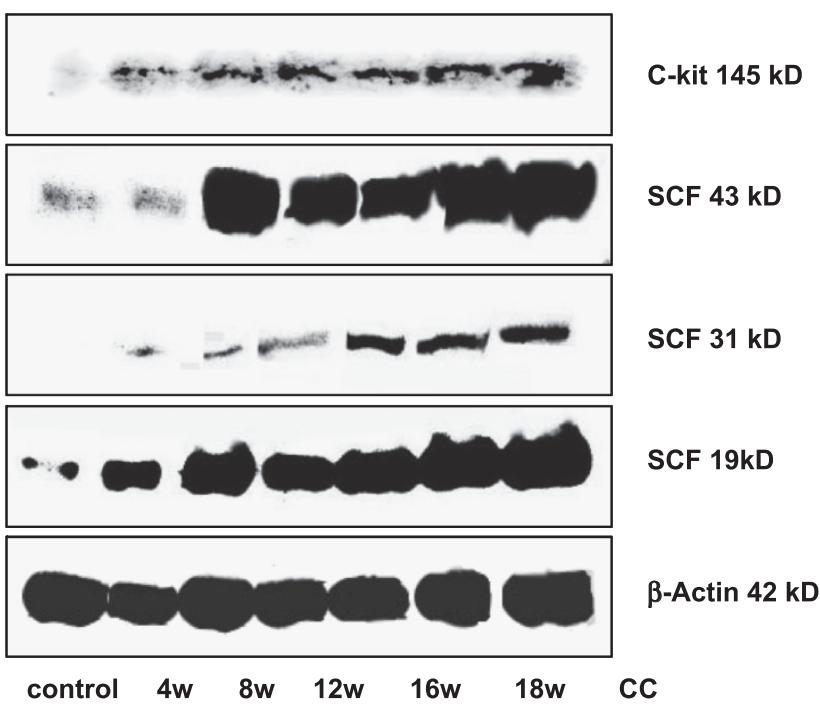

Figure 10 Demonstration of SCF- and c-Kit-protein in rat liver tissue after 18 weeks of TAA administration. Western blot analysis of SCF and c-Kit during CC development. Note that three immunoreactive bands for SCF were observed at 43,31 and $19 \mathrm{kD}$. The c-Kit-protein was detected at $145 \mathrm{kD}$.
SEC (Ct-mean: 23) and in Kupffer cells (Ct-mean: 22), whereas a low expression was detected in hepatocytes (Ct-mean: 35), MFs (Ct-mean: 33) and HSC (Ct-mean: 32-35) of the normal liver (Figure 12b).

\section{DISCUSSION}

The development and progression of primary liver cancers is a complex process. Murine models of hepatocarcinogenesis have recently gained importance in investigating the molecular and cellular abnormalities. ${ }^{30}$ In this study, we aimed to examine the SCF-c-Kit expression pattern in a rat model of $\mathrm{CC}$ at different stages of carcinogenesis.

Immunohistochemical investigations of the normal liver tissue showed SCF positivity in the wall of the hepatic artery and of the portal vein. A positive SCF expression could also be detected in some cells, which were located along the sinusoids, whereas hepatocytes and biliary epithelial cells were SCF negative. Immunohistochemical analysis of the cirrhotic liver displayed numerous SCF-positive cells, which were localized within the fibrotic tissue, as well as within the regenerating liver nodules. Moreover, SCF positivity could be detected in ductular cells of the CC, whereas bile duct epithelial cells, which were located in the adjacent nontumoral tissue, remained SCF-negative. Co-localization with non-parenchymal cell markers confirmed that the SCF-expressing cells are, among others, MFs, SECs and mononuclear phagocytes. Interestingly, immunohistochemical analysis of the c-Kit receptor revealed that hepatocytes of the regenerating nodules, proliferating ductular cells of the fibrotic septa and bile duct epithelial cells of the CC are c-Kit positive.

Up until now, conflicting data exist regarding the immunolocalization of the SCF- and c-Kit-protein in the normal and injured adult liver. Ren et al described a positive staining for SCF-protein in hepatocytes, ${ }^{31}$ which is in
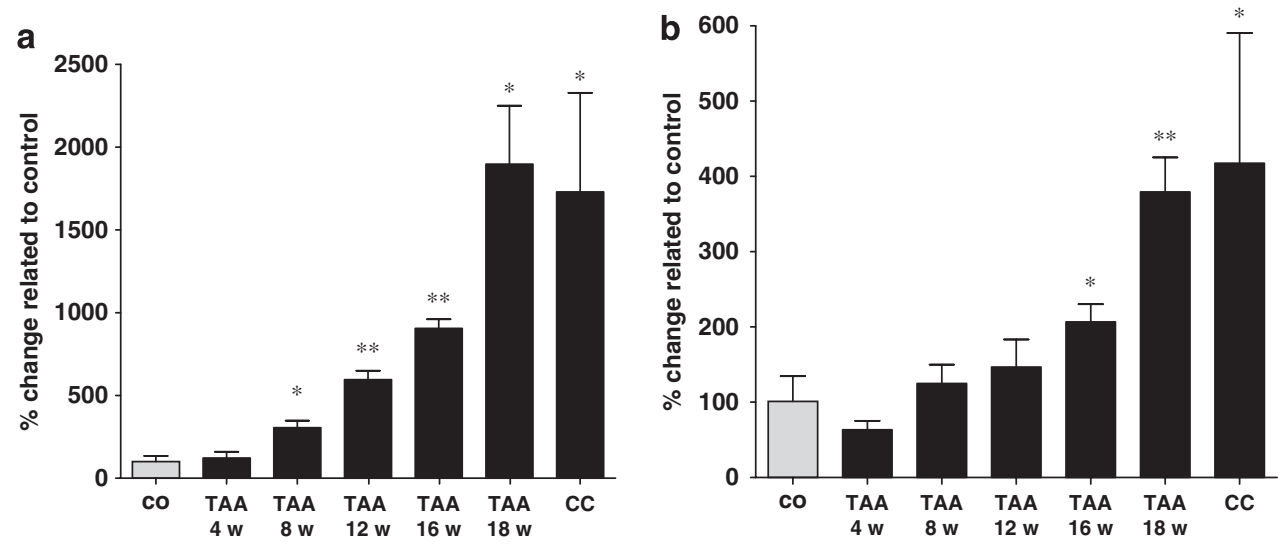

Figure 11 Demonstration of the changes of SCF- and c-Kit-gene expression in rat liver tissue after 18 weeks of TAA administration. PCR analysis of total RNA extracted from the livers showing the SCF- (a) and c-Kit-gene expression (b) during the CC development. Four rats were killed at every time point in the control group (CO) and five rats were killed at every time point in the TAA-treated group (w, week). The differences were statistically significant compared with control livers $\left({ }^{*} P \leq 0.05,{ }^{*} P \leq 0.005\right)$. 

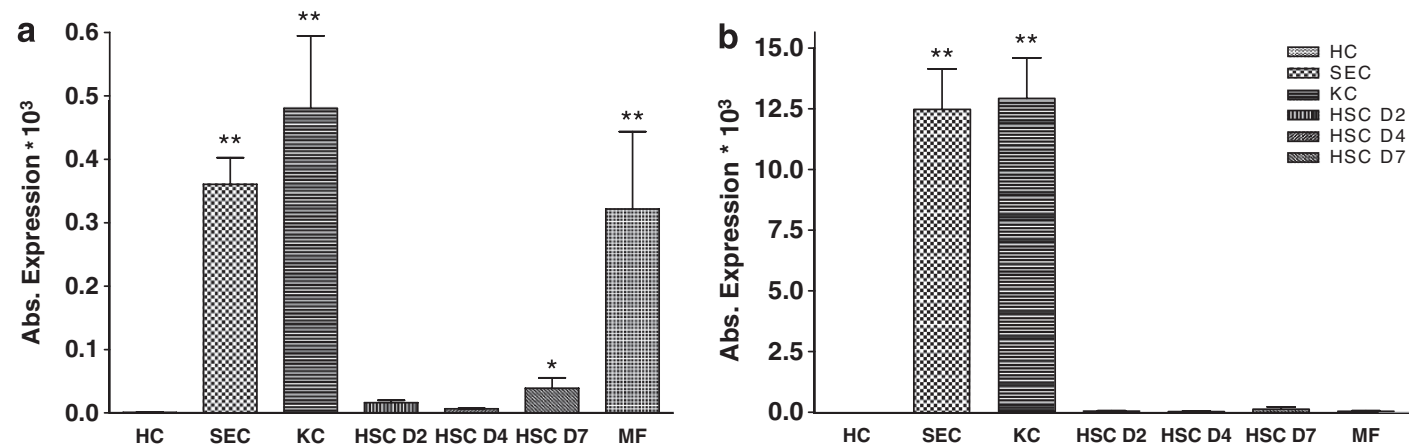

Figure 12 Demonstration of SCF and c-Kit-gene expression in isolated normal rat liver cells. RNA extracted from cell lysates of isolated different rat liver cells (number of cell isolations: 4). SCF- (a) and c-Kit-gene expression (b) was analyzed by real-time PCR using specific primers. A significant difference of the SCF- and c-Kit-mRNA expression was found among the different rat liver cells compared to normal hepatocytes $\left({ }^{*} P \leq 0.05,{ }^{* * P} \leq 0.005\right)$.

contrast to our findings and that of the other investigators findings. ${ }^{32}$ Furthermore, we could not detect a positive SCF staining in the biliary epithelial cells of the normal liver. Even in CC specimens, in which an intense SCF positivity could be found in tumoral bile duct epithelial cells, the biliary epithelial cells of the non-affected biliary tree remained negative for SCF, which is consistent with a former publication by Tsuneyama et $a l^{33}$ Swenson et $a l^{34}$ described that the immunofluorescent SCF expression in normal mice liver could be found predominantly in Kupffer cells, peribiliary cells and in arterial smooth muscle, whereas only a weak expression could be detected in cholangiocytes and no expression was detected in normal hepatocytes. In the 2-acetylaminofluorene/partial hepatectomy rat model, the c-Kit-mRNA expression could be shown in 'oval cells', whereas SCF transcripts were shown in both 'oval cells' and in stellate cells. ${ }^{16,35}$ Baumann et $a l^{36}$ investigated the SCF-c-Kit system in pediatric human liver during acute and chronic liver injury and showed an increase of c-Kit-positive cells in cirrhotic livers.

Comparison analysis of the SCF-mRNA expression from isolated cells of the normal liver revealed that the SECs and Kupffer cells represent the main SCF-expressing cell populations, followed by MFs. Low levels of the SCF-mRNA expression could be detected in normal hepatocytes and in HSC. Although, this method allows determining which cell of the non-parenchymal population may express SCF, the results should be interpreted with caution when discussing the possible source of SCF in vivo this particular model.

The SCF-mRNA expression in liver tissue was significantly upregulated during cholangiocarcinogenesis, starting at week 8 after TAA administration and reaching its maximum at week 18 , when $100 \%$ of the treated animals developed CC. Compared with the SCF-gene expression, the c-Kit-gene expression showed a similar behavior.

SCF, which exists in both soluble and membrane-bound forms, is enzymatically cleaved from the surface of cells during injury and inflammation. ${ }^{37,38}$ Western blot analysis revealed a progressive increase of the soluble and the membrane-bound forms during cholangiocarcinogenesis. The relative importance of each form of SCF is not understood fully, and alterations in the balance between soluble and cell-bound SCF may play a key role in disease states. ${ }^{29}$ Mice which produce only the soluble form of SCF, because of a deletion affecting the transmembrane and cytoplasmic domain, are viable, but have anemia, pigmentation defects and lack tissue mast cells. ${ }^{39}$ Kapur et al described transgenic mice expressing either soluble or membrane-bound forms of SCF. The membrane-bound form-but not the soluble formpartially corrected anemia. In contrast, only the soluble form restored the myeloid progenitor cell numbers, indicating differential functions of the SCF isoforms. ${ }^{40}$

The regeneration of liver tissue after damage is an area of intense investigation, indicating that several factors are involved. ${ }^{41,42}$ SCF, which can be cleaved from the cell surface during inflammatory events, is supposed to be an important factor, protecting livers from acute damage. ${ }^{16,43}$ Earlier studies showed, in murine models of liver injury and in patients with hepatectomy, that SCF levels do increase with the extent of parenchymal loss, whereas patients with fulminant hepatic failure had significantly lower levels of SCF, emphasizing the role of SCF and c-Kit in liver repair. ${ }^{14,44}$ Recent studies have documented that SCF is produced and released in response to hepatic resection, inducing hepatocyte proliferation. Proliferative effects on hepatocytes could be shown both in vitro and in vivo after partial hepatectomy, whereby IL- 6 and TNF- $\alpha$ were supposed to induce hepatocyte production of SCF. ${ }^{15,31}$ Ren et al ${ }^{15}$ described that SCF blockade, either by administration of anti-SCF antibodies or by using genetically altered SCF-deficient mice, inhibits hepatocyte proliferation after partial hepatectomy and replaces the SCF-restored hepatocyte proliferation. These data might support our results, showing for the first time that hepatocytes of the regenerating nodules in cirrhotic livers are able to express c-Kit receptor and, therefore, might be able to react upon SCF stimulation. On the other hand, the expression of c-Kit could also be detected on biliary epithelial cells of CC, 
suggesting that SCF might have, besides its physiological role in liver regeneration, a proliferative effect on c-Kit-expressing tumor cells. Upon binding to its receptor, c-Kit, SCF leads to a dimerization and transphosphorylation. This in turn initiates additional specific signal transduction pathways, including the phosphatidylinositol 3-kinase (PI-3K)-AKT pathway, Src family members and the JAK-STAT pathway, which is important in hepatic regeneration. ${ }^{45,46}$

Chronic inflammation, induced by microbial agents, radiation, endogenous or exogenous chemicals, has been associated with cancer development. ${ }^{47-49}$ Despite the evidence for the role of inflammation in cancer initiation, promotion and progression, the precise mechanism by which the inflammation leads to the development of tumoral cells and eventually to tumor growth is still ill understood. One hypothesis suggests that ROS (reactive oxygen species), released by inflammatory cells, induce DNA damage in proliferating epithelial cells (hepatocytes and/or biliary cells). In our model, inflammatory cells could contribute to cell proliferation by releasing SCF and to DNA damage by releasing ROS. The same cells could then support the survival of SCF-dependent tumor cells.

In this model of the TAA-induced liver injury, inflammation and sequential development of cirrhosis and CC, we showed that the SCF-c-Kit-gene expression increased in cirrhosis and CC compared with normal liver. The kinetics of the SCF and c-Kit expressions at different stages of liver injury raise the possibility that the administration of c-Kitspecific tyrosine kinase inhibitors (eg, imatinib) may prevent the development of CC. A similar result could be obtained by inhibiting SCF and/or c-Kit production by administering SCF- and/or c-Kit-specific siRNA. Such studies are underway by using the model described in this paper.

1. Nakanuma $Y$, Sasaki $M$, Ikeda $H$, et al. Pathology of peripheral intrahepatic cholangiocarcinoma with reference to tumorigenesis. Hepatol Res 2008;38:325-334.

2. Ishikawa K, Sasaki A, Haraguchi N, et al. A case of an alpha-fetoproteinproducing intrahepatic cholangiocarcinoma suggests probable cancer stem cell origin. Oncologist 2007;12:320-324.

3. Alison MR. Liver stem cells: implications for hepatocarcinogenesis. Stem Cell Rev 2005;1:253-260.

4. Roskams T. Liver stem cells and their implication in hepatocellular and cholangiocarcinoma. Oncogene 2006;25:3818-3822.

5. Sano T, Shimada K, Sakamoto $Y$, et al. Prognosis of perihilar cholangiocarcinoma: hilar bile duct cancer versus intrahepatic cholangiocarcinoma involving the hepatic hilus. Ann Surg Oncol 2008:15:590-599.

6. Yachimski P, Pratt DS. Cholangiocarcinoma: natural history, treatment, and strategies for surveillance in high-risk patients. J Clin Gastroentero 2008:42:178-190.

7. Khan SA, Miras $A$, Pelling $M$, et al. Cholangiocarcinoma and its management. Gut 2007;56:1755-1756.

8. Giannelli G, Quaranta V, Antonaci S. Tissue remodelling in liver diseases. Histol Histopathol 2003;18:1267-1274.

9. Allavena P, Sica A, Solinas G, et al. The inflammatory microenvironment in tumor progression: the role of tumor-associated macrophages. Crit Rev Oncol Hematol 2008;66:1-9.

10. Blechacz BR, Gores GJ. Cholangiocarcinoma. Clin Liver Dis 2008;12:131-150.
11. Jagani Z, Khosravi-Far R. Cancer stem cells and impaired apoptosis. Adv Exp Med Biol 2008;615:331-344.

12. Galli SJ, Zsebo KM, Geissler EN. The kit ligand, stem cell factor. Adv Immunol 1994;55:1-96.

13. Geissler EN, Liao M, Brook JD, et al. Stem cell factor (SCF), a novel hematopoietic growth factor and ligand for c-kit tyrosine kinase receptor, maps on human chromosome 12 between 12 q14.3 and 12qter. Somat Cell Mol Genet 1991;17:207-214.

14. Krieg A, Schulte Am EJ, Schmelzle M, et al. Stem cell factor levels do increase in patients subsequent to hepatectomy with the extent of parenchymal loss. Transplant Proc 2006;38:3556-3558.

15. Ren X, Hogaboam C, Carpenter A, et al. Stem cell factor restores hepatocyte proliferation in IL-6 knockout mice following $70 \%$ hepatectomy. J Clin Invest 2003;112:1407-1418.

16. Simpson K, Hogaboam CM, Kunkel SL, et al. Stem cell factor attenuates liver damage in a murine model of acetaminophen-induced hepatic injury. Lab Invest 2003;83:199-206.

17. Armbrust $T$, Batusic $D$, Ringe $B$, et al. Mast cells distribution in human liver disease and experimental rat liver fibrosis. Indications for mast cell participation in development of liver fibrosis. J Hepatol 1997;26: 1042-1054.

18. Reber L, Da Silva CA, Frossard N. Stem cell factor and its receptor c-kit as targets for inflammatory diseases. Eur J Pharmacol 2006;533:327-340.

19. Toyota M, Hinoda Y, Takaoka A, et al. Expression of c-kit and kit ligand in human colon carcinoma cells. Tumour Biol 1993;14:295-302.

20. Sun L, Hui AM, Su Q, et al. Neuronal and glioma-derived stem cell factor induces angiogenesis within the brain. Cancer Cell 2006;9:287-300.

21. Turner AM, Zsebo KM, Martin F, et al. Nonhematopoietic tumor cell lines express stem cell factor and display c-kit receptors. Blood 1992;80:374-381.

22. Yasuda A, Sawai $H$, Takahashi $H$, et al. Stem cell factor/c-kit receptor signaling enhances the proliferation and invasion of colorectal cance cells through the PI3K/Akt pathway. Dig Dis Sci 2007;52:2292-2300.

23. Krystal GW, Hines SJ, Organ CP. Autocrine growth of small cell lung cancer mediated by coexpression of c-kit and stem cell factor. Cancer Res 1996;56:370-376.

24. Yeh CN, Maitra A, Lee KF, et al. Thioacetamide-induced intestinal-type cholangiocarcinoma in rat: an animal model recapitulating the multi-stage progression of human cholangiocarcinoma. Carcinogenesis 2004;25:631-636.

25. Neubauer K, Lindhorst A, Tron K, et al. Decrease of PECAM-1-geneexpression induced by proinflammatory cytokines IFN-gamma and TNF-alpha is reversed by TGF-beta in sinusoidal endothelial cells and hepatic mononuclear phagocytes. BMC Physiol 2008;8:9.

26. Dudas J, Mansuroglu T, Batusic D, et al. Thy- 1 is an in vivo and in vitro marker of liver myofibroblasts. Cell Tissue Res 2007;329:503-514.

27. Dudas J, Mansuroglu T, Moriconi F, et al. Altered regulation of Prox1-gene-expression in liver tumors. BMC Cancer 2008;8:92.

28. El Kossi MM, Haylor JL, Johnson TS, et al. Stem cell factor in a rat model of serum nephrotoxic nephritis. Nephron Exp Nephrol 2008;108:e1-e10.

29. Ashman LK. The biology of stem cell factor and its receptor C-kit. Int J Biochem Cell Biol 1999;31:1037-1051.

30. Newell $P$, Villanueva A, Friedman $\mathrm{SL}$, et al. Experimental models of hepatocellular carcinoma. J Hepatol 2008;48:858-879.

31. Ren X, Hu B, Colletti L. Stem cell factor and its receptor, c-kit, are important for hepatocyte proliferation in wild-type and tumor necrosis factor receptor- 1 knockout mice after $70 \%$ hepatectomy. Surgery 2008;143:790-802.

32. Fujio K, Hu Z, Evarts RP, et al. Coexpression of stem cell factor and c-kit in embryonic and adult liver. Exp Cell Res 1996;224:243-250.

33. Tsuneyama $\mathrm{K}$, Kono $\mathrm{N}$, Yamashiro $\mathrm{M}$, et al. Aberrant expression of stem cell factor on biliary epithelial cells and peribiliary infiltration of c-kitexpressing mast cells in hepatolithiasis and primary sclerosing cholangitis: a possible contribution to bile duct fibrosis. J Pathol 1999;189:609-614.

34. Swenson ES, Kuwahara R, Krause DS, et al. Physiological variations of stem cell factor and stromal-derived factor-1 in murine models of liver injury and regeneration. Liver Int 2008;28:308-318.

35. Fujio K, Evarts RP, Hu Z, et al. Expression of stem cell factor and its receptor, c-kit, during liver regeneration from putative stem cells in adult rat. Lab Invest 1994;70:511-516. 
36. Baumann U, Crosby HA, Ramani $P$, et al. Expression of the stem cell factor receptor c-kit in normal and diseased pediatric liver: identification of a human hepatic progenitor cell? Hepatology 1999;30:112-117.

37. Pandiella A, Bosenberg MW, Huang EJ, et al. Cleavage of membraneanchored growth factors involves distinct protease activities regulated through common mechanisms. J Biol Chem 1992;267:24028-24033.

38. Huang EJ, Nocka KH, Buck J, et al. Differential expression and processing of two cell associated forms of the kit-ligand: KL-1 and KL-2. Mol Biol Cell 1992;3:349-362.

39. Russell ES. Hereditary anemias of the mouse: a review for geneticists. Adv Genet 1979;20:357-459.

40. Kapur R, Majumdar M, Xiao X, et al. Signaling through the interaction of membrane-restricted stem cell factor and c-kit receptor tyrosine kinase: genetic evidence for a differential role in erythropoiesis. Blood 1998;91:879-889.

41. Ramadori G, Moriconi F, Malik I, et al. Physiology and pathophysiology of liver inflammation, damage and repair. J Physiol Pharmaco 2008;59(Suppl 1):107-117.
42. Michalopoulos GK. Liver regeneration. J Cell Physiol 2007;213:286-300.

43. Hu B, Colletti LM. Stem cell factor and c-kit are involved in hepatic recovery after acetaminophen-induced liver injury in mice. Am J Physiol Gastrointest Liver Physiol 2008;295:G45-G53.

44. Okumoto K, Saito T, Onodera M, et al. Serum levels of stem cell factor and thrombopoietin are markedly decreased in fulminant hepatic failure patients with a poor prognosis. J Gastroenterol Hepatol 2007;22:1265-1270.

45. Jacobs-Helber SM, Penta K, Sun Z, et al. Distinct signaling from stem cell factor and erythropoietin in HCD57 cells. J Biol Chem 1997;272:6850-6853.

46. Roskoski Jr R. Signaling by kit protein-tyrosine kinase-the stem cell factor receptor. Biochem Biophys Res Commun 2005;337:1-13.

47. Hussain SP, Harris CC. Inflammation and cancer: an ancient link with novel potentials. Int J Cancer 2007;121:2373-2380.

48. Lu H, Ouyang $W$, Huang $C$. Inflammation, a key event in cancer development. Mol Cancer Res 2006;4:221-233.

49. de Visser KE, Coussens LM. The inflammatory tumor microenvironment and its impact on cancer development. Contrib Microbiol 2006;13:118-137. 